ARTICLE

https://doi.org/10.1038/s41467-019-11345-z

\title{
Catalytic enantioselective addition of organometallics to unprotected carboxylic acids
}

\author{
Xingchen $\operatorname{Yan}^{1} \&$ Syuzanna R. Harutyunyan (1) ${ }^{1}$
}

Conjugate addition of organometallics to carbonyl based Michael acceptors is a widely used method that allows the building of new carbon-carbon (C-C) bonds and the introduction of chirality in a single step. However, conjugate additions to the simplest Michael acceptors, namely unprotected, unsaturated carboxylic acids, are considered to be prohibited by the fact that acid-base reactions overpower any other type of reactivity, including nucleophilic addition. Here we describe a transient protecting group strategy that allows efficient catalytic asymmetric additions of organomagnesium reagents to unprotected $\alpha, \beta$-unsaturated carboxylic acids. This unorthodox pathway is achieved by preventing the formation of unreactive carboxylate salts by means of a reactive intermediate, allowing modifications of the carbon chain to proceed unhindered, while the stereochemistry is controlled with a chiral copper catalyst. A wide variety of $\beta$-chiral carboxylic acids, obtained with excellent enantioselectivities and yields, can be further transformed into valuable molecules through for instance catalytic decarboxylative cross-coupling reactions.

\footnotetext{
${ }^{1}$ Stratingh Institute for Chemistry, University of Groningen, Nijenborgh 4, 9747 AG Groningen, The Netherlands. Correspondence and requests for materials should be addressed to S.R.H. (email: s.harutyunyan@rug.nl)
} 
nprotected carboxylic acids are essential constituents of biologically active compounds and essential precursors in the synthesis of numerous useful derivatives ${ }^{1-3}$. As such, they are often produced industrially and used in the production of polymers, pharmaceuticals, solvents, and food additives. One of the simplest ways to generate target carboxylic acids would exist of taking simple, readily available variants, and modifying the carbon chain by, for example, introducing functional groups, forming additional carbon-carbon bonds, and introducing chirality. This implies (asymmetric) conjugate addition of organometallics, a highly important and widely used method, that allows the introduction of carbon-carbon $(\mathrm{C}-\mathrm{C})$ bonds and chirality in a single ste ${ }^{4-7}$. However, applying this method to unprotected $\alpha, \beta$ unsaturated carboxylic acids is inhibited by a fundamental problem, namely that upon mixing with common organometallics the acidity of the carboxylic acids and the basicity of the organometallics invariably leads to deprotonation and the formation of carboxylate salts, as the organometallic functions primarily as a base instead of as a nucleophile (Fig. 1a). Once the salt is formed, further organic reactions become unfeasible because of the inherent low reactivity and insolubility of salts in organic solvents. Consequently, even though the first effort to do this, in a non-enantioselective manner, dates back to $1953^{8}$, and despite many further attempts ${ }^{9-13}$, to our knowledge no examples of direct applications of unsaturated carboxylic acids in either catalytic or stoichiometric enantioselective reactions with hard organometallics, nor with organoboron or organosilicon reagents, are known.

This is unfortunate, given that carboxylic acids are not just the main precursors of various carbonyl compounds and common components of biologically active compounds but, perhaps even more importantly, because of their potential for application in decarboxylative coupling reactions that have witnessed tremendous progress in recent years and would allow access to a variety of $\beta$-chiral functionalized molecules in a simple manner (Fig. 1b) ${ }^{14-19}$. Therefore, developing a successful strategy for asymmetric conjugate additions to carboxylic acids would also allow direct access to $\beta$-chiral carboxylic acids and other chiral functional molecules, starting from simple substrates and without any derivatizations or protecting and deprotecting steps.
So far, chiral $\beta$-substituted carboxylic acids are mainly obtained by kinetic resolution or asymmetric hydrogenation reactions ${ }^{20-23}$. However, these methods are often limited to aryl substituents in the $\beta$-position of the substrate, require precious transition metal catalysts and make use of molecular frameworks, in which all the carbons have already been preinstalled. Thus, all $\mathrm{C}-\mathrm{C}$ bonds must be formed in preceding reactions. Another common, indirect way is through asymmetric additions to premade $\alpha, \beta$-unsaturated esters, thioesters, or amides using chiral catalysts or chiral auxiliaries, followed by a hydrolysis step ${ }^{4-7,24-28}$.

Our goal was to develop a general platform for direct catalytic synthesis of enantiopure $\beta$-substituted carboxylic acids from simple carboxylic acid-building blocks via $\mathrm{C}-\mathrm{C}$ bond-forming reactions. Making this possible via additions of organometallics directly to unprotected $\alpha, \beta$-unsaturated carboxylic acids would present a unique and important step forward in organic synthesis, but requires circumventing the fundamental issue of the acid-base reactions hindering the desired carbon-carbon bondforming process.

Here, we describe a strategy that allows highly efficient direct catalytic asymmetric additions of organomagnesium reagents to unprotected $\alpha, \beta$-unsaturated carboxylic acids by preventing the formation of unreactive carboxylate salts. This allows modifications of the carbon chain to proceed unhindered, while the stereochemistry is controlled with a chiral copper catalyst. The catalytic system is scalable, does not require cryogenic temperatures, does not rely on precious metals, and allows the catalyst to be reused.

\section{Results}

Racemic reaction development. We realized that the fundamental issue of the acid-base reactions leading to the formation of unreactive carboxylate salts could be circumvented by in situ formation of a reactive intermediate $\mathbf{B}$ from or instead of the carboxylate salt A (Fig. 2a). This would require an intermediate that is reactive toward enantioselective conjugate additions, is easily formed under organometallic addition reaction conditions and would lead to the final carboxylic acid product without additional chemical reactions, simply upon reaction quenching or product isolation ${ }^{29,30}$. We set out to identify a compound that

a

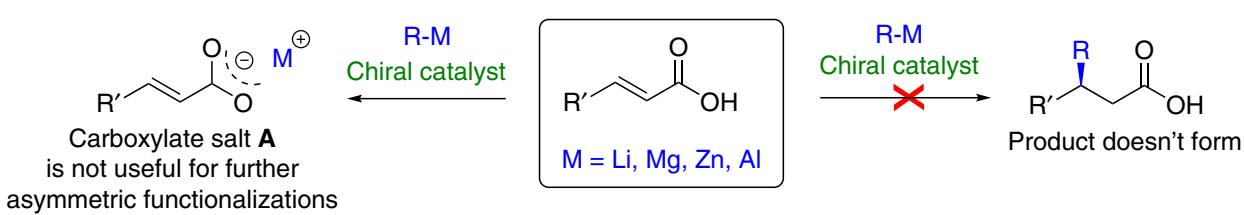

b

Straightforward functionalizations of chiral carboxylic acids

Products derived from application of chiral carboxylic acids in decarboxylative cross-couplings

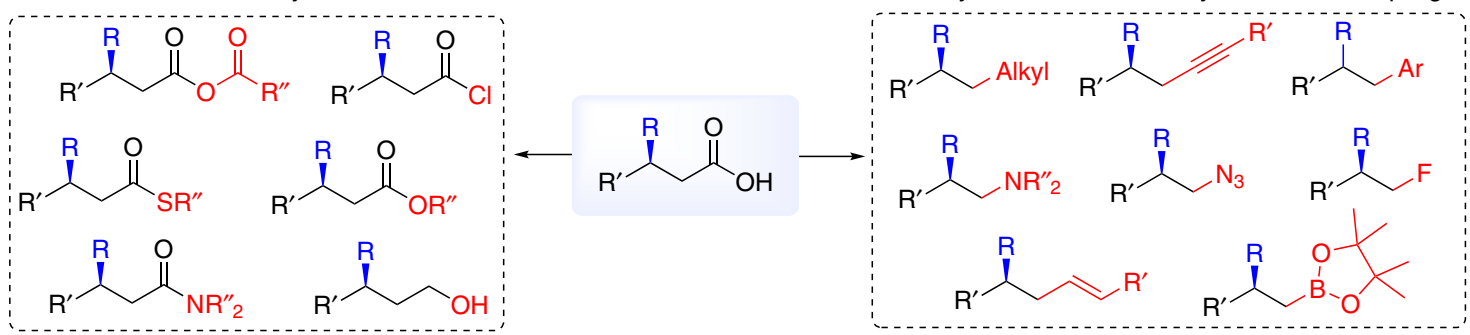

Fig. 1 State of the art in conjugate additions to unsaturated carboxylic acids and potential value of addition products. a Fundamental problem that prevents the development of conjugate additions to unprotected unsaturated carboxylic acids: mixing of organometallics with carboxylic acids leads to an acid-base reaction, resulting in a carboxylate salt $\mathbf{A}$ nearly unreactive toward further reactions. $\mathbf{b}$ Overview of transformations of the carboxylic acid functional group leading to its chiral derivatives and new structural motives: carboxylic acids can undergo straightforward functionalization and decarboxylative crosscoupling reactions 


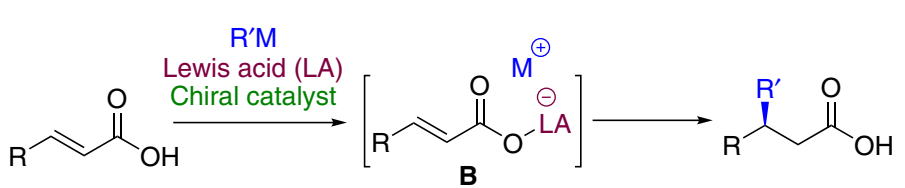

\begin{tabular}{|c|c|c|c|c|}
\hline \multicolumn{5}{|c|}{ Racemic reaction in the absence of chiral catalyst } \\
\hline \multirow{2}{*}{ Entry } & \multicolumn{3}{|c|}{ Order of addition of reagents } & \multirow{2}{*}{$\begin{array}{c}\text { Conv. to } 2 a \\
(\%)\end{array}$} \\
\hline & 1 (equiv.) & 2 (equiv.) & 3 (equiv.) & \\
\hline 1 & EtMgBr (2) & - & - & 1 \\
\hline 2 & EtMgBr (2) & $\mathrm{BF}_{3} . \mathrm{Et}_{2} \mathrm{O}(2)$ & - & 1 \\
\hline 3 & EtMgBr (2) & $\mathrm{Me}_{3} \mathrm{SiOTf}(2)$ & - & 6 \\
\hline 4 & $\mathrm{BF}_{3} \cdot \mathrm{Et}_{2} \mathrm{O}(2)$ & EtMgBr (2) & - & 10 \\
\hline 5 & $\mathrm{Me}_{3} \mathrm{SiOTf}(2)$ & EtMgBr (2) & - & 52 \\
\hline 6 & nBuLi (1) & $\mathrm{Me}_{3} \mathrm{SiOTf}(2)$ & EtMgBr (1) & 74 \\
\hline 7 & $\mathrm{NaH}(1)$ & $\mathrm{Me}_{3} \mathrm{SiOTf}(2)$ & EtMgBr (1) & 66 \\
\hline
\end{tabular}

\section{$C_{\text {Entries } 2 \text { and } 3}$

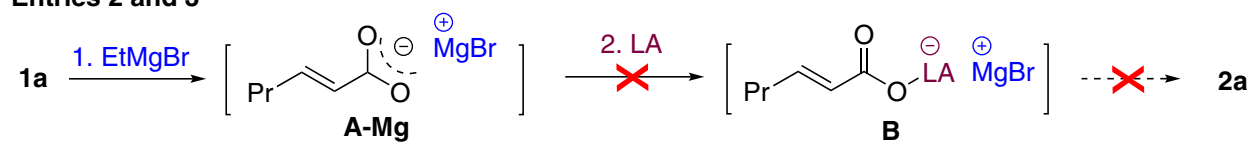

Entry 4

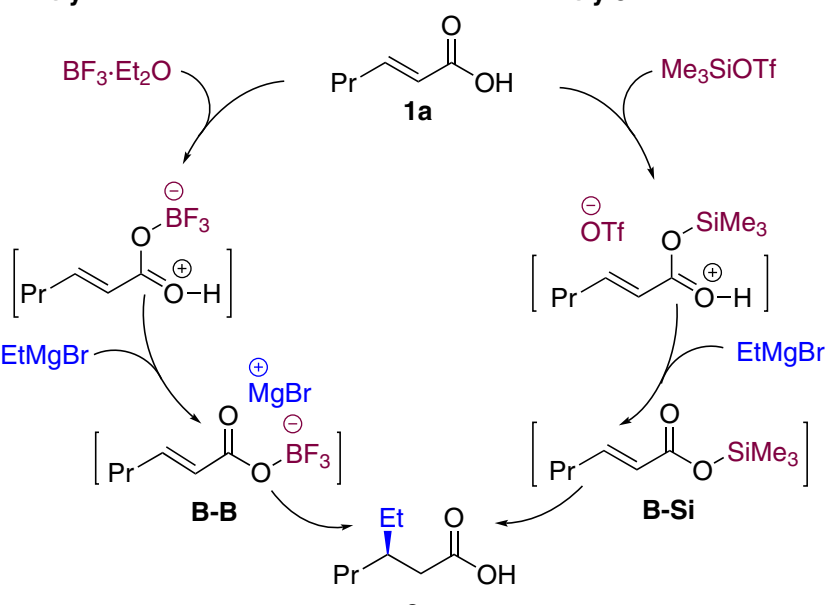

Entry 6

Entry 7

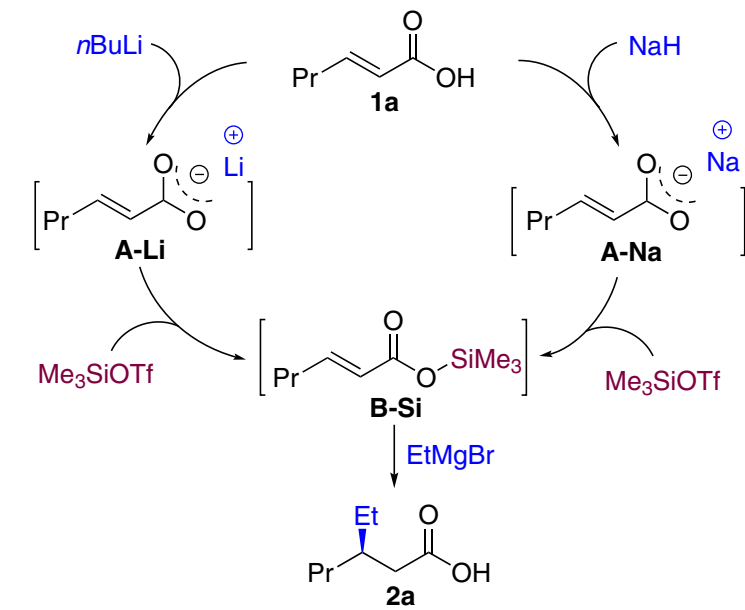

Fig. 2 Reaction development. a Our approach, based on the use of Lewis acid to promote in situ formation of a transient intermediate $\mathbf{B}$ that can undergo conjugate addition of organometallic reagent. $\mathbf{b}$ Conjugate addition of $\mathrm{EtMgBr}$ to the substrate $\mathbf{1 a}$ in the absence of chiral catalyst with varying conditions. c Rationalization of the experimental data in entries 1-7 obtained for conjugate addition of EtMgBr in various conditions

fulfils all of these stringent requirements, drawing on our past experience with combining Lewis acids (LA) and highly reactive organometallics in conjugate additions ${ }^{28,31,32}$. We speculated that using common LA such as trimethylsilyl triflate $\left(\mathrm{Me}_{3} \mathrm{SiOTf}\right.$, $\left.\mathrm{OTf}=\mathrm{OSO}_{2} \mathrm{CF}_{3}\right)$ or boron trifluoride $\left(\mathrm{BF}_{3} \cdot \mathrm{Et}_{2} \mathrm{O}\right)$ as electrophiles might lead to the formation of soluble and unstable silyl intermediates or boron intermediates, with anticipated high reactivity toward conjugate addition of Grignard reagents and can lead directly to the final unprotected carboxylic acid product. This particular choice of LA was based on our previous studies, where these LA were found to be compatible with Grignard reagents and successfully used to enhance reaction rates with various electrophiles ${ }^{28,31,32}$.

To address the feasibility of this strategy, we first investigated the noncatalyzed addition of EtMgBr to trans-2-hexenoic acid 1a (Fig. 2b). At $0{ }^{\circ} \mathrm{C}$, a complex mixture of products (including $20 \%$ of 2 a) was observed in the absence of any catalyst or additives, indicating that the system is dominated by various side reactions at such a relatively high temperature. As expected, no conversion of the substrate la was seen at $-55^{\circ} \mathrm{C}$ (Fig. 2b, entry 1), because only the $\mathbf{M g}$-carboxylate $\mathbf{A}-\mathbf{M g}$ was formed and precipitated out of the reaction mixture (and hydrolyzed back to the substrate during quenching of the reaction). We proceeded by adding the reactive $\mathrm{LA} \mathrm{Me}_{3} \mathrm{SiOTf}$ or $\mathrm{BF}_{3} \cdot \mathrm{Et}_{2} \mathrm{O}$ to the mixture, hoping they would react with the $\mathbf{M g - c a r b o x y l a t e ~} \mathbf{A}-\mathbf{M g}$ to form a more reactive boron or silyl intermediate $\mathbf{B}-\mathbf{S i}$ or $\mathbf{B}-\mathbf{B}$ depending on the Lewis acid used), but unfortunately this only had a minor effect (Fig. 2b, c, entries 2 and 3). Anticipating poor reactivity of the $\mathbf{M g}$-carboxylate $\mathbf{A - M g}$ toward the silyl and boron electrophiles, we decided to add the latter first and EtMgBr second, and to our delight this yielded the addition product $\mathbf{2 a}$ with $10 \%$ conversion with $\mathrm{BF}_{3} \cdot \mathrm{Et}_{2} \mathrm{O}$ and $52 \%$ conversion with $\mathrm{Me}_{3} \mathrm{SiOTf}$ (Fig. 2b, entries 4 and 5, respectively). The much higher conversion toward the addition product $\mathbf{2 a}$ obtained with $\mathrm{Me}_{3} \mathrm{SiOTf}$ can be rationalized by the higher electrophilicity of the latter in comparison with $\mathrm{BF}_{3} \cdot \mathrm{Et}_{2} \mathrm{O}$.

We believe that the sequence of addition of the reagents is important, because the nucleophilicity of the Mg-carboxylate A-Mg is insufficient to react with the boron or silyl electrophile (presumably due to aggregates formation), and thus nearly no reactive intermediates are generated (Fig. 2b, c, entries 2 and 3). Conversely, when either Lewis acid is added first, it combines with the carboxylic acid 1a to form an initial complex, after which addition of EtMgBr leads to abstraction of the proton and concomitant formation of intermediates $\mathbf{B}-\mathbf{B}$ or $\mathbf{B}-\mathbf{S i}$ (depending on the Lewis acid used), that are reactive toward conjugate addition (Fig. 2b, c, entries 4 and 5, respectively). Hence, the formation of the $\mathbf{M g}$-carboxylate $\mathbf{A - M g}$ is avoided, and conjugate 


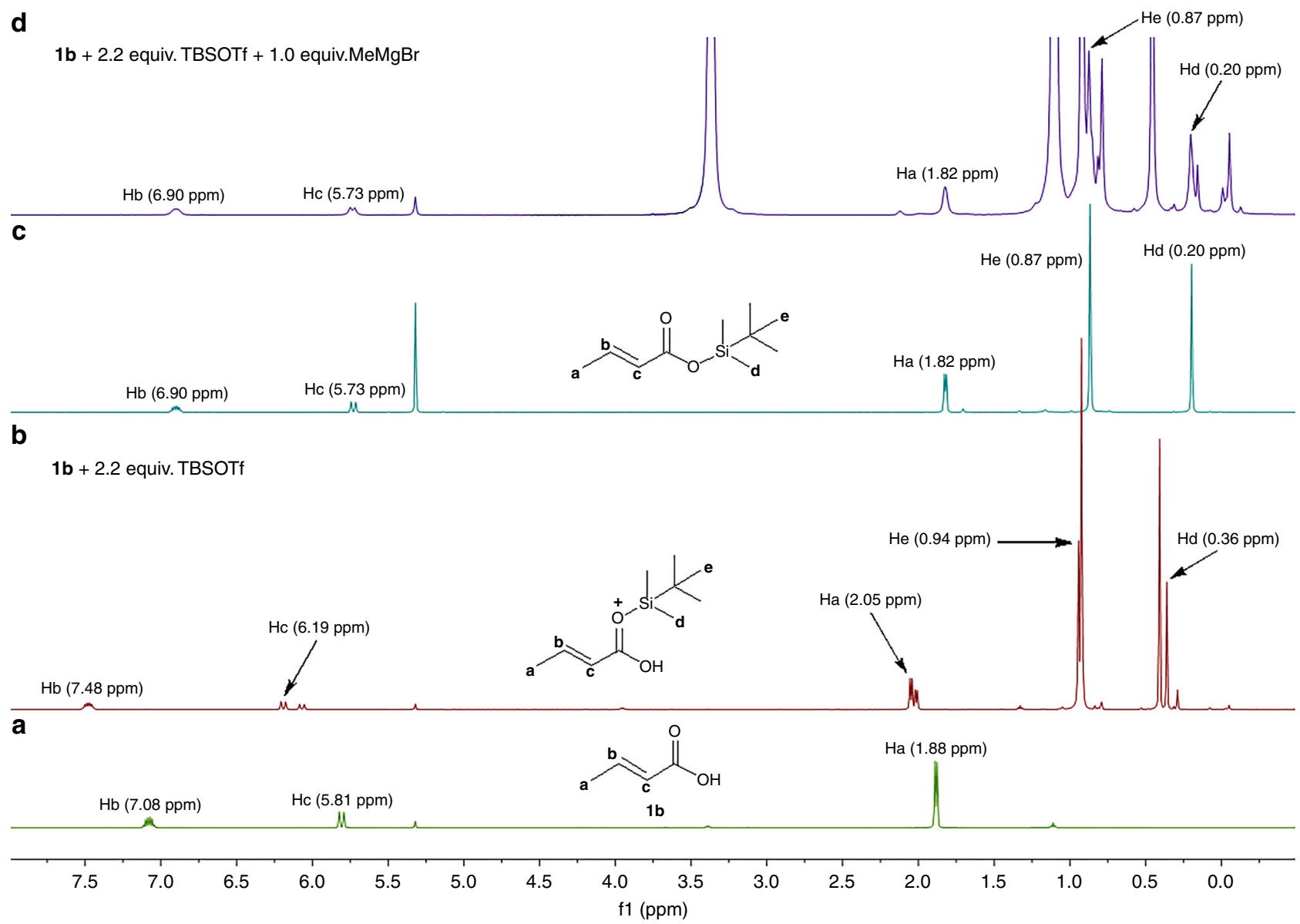

Fig. $3^{1} \mathrm{H}$ NMR experiments carried out in $\mathrm{CD}_{2} \mathrm{Cl}_{2}$ at $-55^{\circ} \mathrm{C}$ using substrate $\mathbf{1 b}, t \mathrm{BuMe}_{2} \mathrm{SiOTf}$ and $\mathrm{MeMgBr}$. a Crotonic acid $\mathbf{1 b}$. b Mixture of $\mathbf{1 b}$ with 2.2 equiv. of $t \mathrm{BuMe}{ }_{2} \mathrm{SiOTf}$. $\mathbf{c}$ Isolated pure $t \mathrm{BuMe}{ }_{2} \mathrm{Si}$-ester of $\mathbf{1 b}$. $\mathbf{d}$ Mixture of $\mathbf{1 b}$ with 2.2 equiv. of $t \mathrm{BuMe}_{2} \mathrm{SiOTf}$ followed by addition of 1.0 equiv. of $\mathrm{MeMgBr}$

addition to form the product $\mathbf{2 a}$ can proceed. To get further support for this rationalization, we attempted to observe both the silyl and the boron intermediates derived from $\mathrm{Me}_{3} \mathrm{SiOTf}$ and $\mathrm{BF}_{3} \cdot \mathrm{Et}_{2} \mathrm{O}$, respectively, using ${ }^{1} \mathrm{H}$ NMR spectroscopy (Fig. 3). However, we failed to do so due to the apparent low stability of the $\mathrm{Me}_{3} \mathrm{Si}$ - and $\mathrm{BF}_{3}$ intermediates. To overcome this problem, we decided to switch to a more bulky $t \mathrm{BuMe}_{2} \mathrm{Si}$ intermediate, which is expected to be more stable and could derive from $t \mathrm{BuMe}_{2}$ SiOTf. First, we carried out the conjugate addition reaction in the same conditions as those of entry 5 in Fig. $2 \mathrm{~b}$, using $t \mathrm{BuMe}_{2} \mathrm{SiOTf}$ instead of $\mathrm{Me}_{3} \mathrm{SiOTf}$. Similar results were obtained in terms of conversion to the addition product, but the product was obtained as a mixture of protected and free carboxylic acid 2a. We then carried out ${ }^{1} \mathrm{H}$ NMR spectroscopic experiments using $t \mathrm{BuMe}_{2}$ SiOTf and crotonic acid $\mathbf{1 b}$ instead of $\mathbf{1 a}$ in order to have simpler ${ }^{1} \mathrm{H}$ NMR spectra (Fig. 3). NMR spectroscopic measurements were carried out for four samples derived from (a) crotonic acid $\mathbf{1 b}$; (b) mixing $\mathbf{1 b}$ with 2.2 equiv. of $t \mathrm{BuMe}_{2} \mathrm{SiOTf}$; (c) synthesized and isolated $t \mathrm{BuMe} \mathrm{B}_{2} \mathrm{Si}$-ester of $\mathbf{1 b}$; and (d) mixing $\mathbf{1 b}$ with 2.2 equiv. of $t \mathrm{BuMe} \mathrm{SiOTf}_{2}$ followed by addition of 1.0 equiv. of $\mathrm{MeMgBr}$. Upon addition of $t \mathrm{BuMe}_{2} \mathrm{SiOTf}$ to $\mathbf{1 b}$, a new species appeared, corresponding to a complex between the two reagents (Fig. 3b). Addition of 1 equiv. of $\mathrm{MeMgBr}$ (just enough to deprotonate but not to be added) led to the formation of the $t \mathrm{BuMe}_{2} \mathrm{Si}$-ester of $\mathbf{1 b}$ with signals comparable with that of independently synthesized and isolated $t \mathrm{BuMe}_{2} \mathrm{Si}$-ester of $\mathbf{1 b}$ (compare Fig. 3c, d). These results confirm indeed that $t \mathrm{BuMe}_{2} \mathrm{SiOTf}$ allows in situ protection of $1 \mathrm{a}$, and that $\mathrm{Me}_{3} \mathrm{SiOTf}$ acts as a traceless protecting group for carboxylic acids and enables the conjugate addition reaction. We assume that $\mathrm{BF}_{3} \cdot \mathrm{Et}_{2} \mathrm{O}$ works in a similar manner to $\mathrm{Me}_{3} \mathrm{SiOTf}$. The importance of our strategy of in situ generation of transient intermediates is further highlighted by the difficulties to access pure isolated $\mathrm{BF}_{3^{-}}$and TMS-protected unsaturated carboxylic acids. Our attempts to synthesize and isolate these compounds independently (even more bulky and stable silyl esters) resulted in a very low yields (below 20\%) and tedious procedures for purification.

To investigate whether carboxylate salts are in general unreactive toward the formation of silyl or boron intermediate or whether this depends on the nature of the metal ion, Li and Na-carboxylates $\mathbf{A}-\mathbf{L i}$ and $\mathbf{A}-\mathbf{N a}$ were prepared from $n \mathrm{BuLi}$ and $\mathrm{NaH}$, respectively, and subjected to the reaction with $\mathrm{Me}_{3} \mathrm{SiOTf}$ and EtMgBr (Fig. 2b, c, entries 6 and 7). Now the silyl intermediate $\mathbf{B}-\mathbf{S i}$ was formed in both cases, and addition of 1 equiv. of $\mathrm{EtMgBr}$ resulted in the formation of the product $2 \mathrm{a}$ with 74 and 66\% conversions, respectively (Fig. 2b, c, entries 6 and 7). These results indicate that once the intermediate $\mathbf{B}-\mathbf{S i}$ is formed, conjugate addition works well, but that when the metal carboxylate $\mathbf{A}$ is formed first, the success of the reaction depends on the counter ions (Fig. 1c). Since metal-carboxylates A-Mg, $\mathbf{A}-\mathbf{L i}$, and $\mathbf{A}-\mathbf{N a}$ are all poorly soluble and precipitate in the reaction solvent, the differing reactivities could also originate from solubility differences. However, we found that the solubility of Li-carboxylate $\mathbf{A}-\mathbf{L i}$ and $\mathrm{Na}$-carboxylate $\mathbf{A}-\mathbf{N a}$ is lower than that of Mg-carboxylate $\mathbf{A - M g}$. More specifically, the solubilities of $\mathbf{A}-\mathbf{M g}$ and $\mathbf{A}-\mathbf{N a}$ in $t$ BuOMe are $0.4318 \mathrm{mM}$ and $0.1225 \mathrm{mM}$, respectively, while solubility of $\mathbf{A}-\mathbf{L i}$ is under ${ }^{1} \mathrm{H}$ NMR detection limit (see Supplementary Figs. 1-3). Thus the difference in 
Table 1 Development of the catalytic system for direct asymmetric conjugate addition of EtMgBr to carboxylic acid $1 a^{a}$

\begin{tabular}{|c|c|c|c|c|c|c|}
\hline \multirow[b]{2}{*}{ Entry } & \multirow[b]{2}{*}{$\mathrm{L} / \mathrm{Cu}(\mathrm{I})$} & \multirow{2}{*}{$\begin{array}{l}{ }_{(R, S)-\mathrm{L} 1} \\
\text { LA }\end{array}$} & $\begin{array}{c}\mathrm{LA}, \mathrm{EtMgBr} \\
\mathrm{L}(6 \mathrm{~mol} \%) \\
\mathrm{CuBr} \cdot \mathrm{SMe}_{2}(5 \mathrm{~mol} \%)\end{array}$ & \multirow[t]{2}{*}{$\left(\mathrm{Tol}_{2}\right)_{2}$} & \multirow[b]{2}{*}{ Conv. [\%] ${ }^{b}$} & \multirow[b]{2}{*}{ ee $[\%]^{c}$} \\
\hline & & & Solvent & & & \\
\hline 1 & L1/Cu(I) & - & $\mathrm{CH}_{2} \mathrm{Cl}_{2}$ & -78 & 0 & - \\
\hline 2 & L1/Cu(I) & - & $\mathrm{CH}_{2} \mathrm{Cl}_{2}$ & 0 & $79^{d}$ & Rac \\
\hline 3 & $\mathbf{L 1} / \mathrm{Cu}(\mathrm{I})$ & $\mathrm{Me}_{3} \mathrm{SiOTf}$ & $\mathrm{CH}_{2} \mathrm{Cl}_{2}$ & -78 & 74 & 47 \\
\hline 4 & $\mathbf{L 2} / \mathrm{Cu}(\mathrm{I})$ & $\mathrm{Me}_{3} \mathrm{SiOTf}$ & $\mathrm{CH}_{2} \mathrm{Cl}_{2}$ & -78 & 70 & 9 \\
\hline 10 & L4/Cu(I) & $\mathrm{Me}_{3} \mathrm{SiOTf}$ & Ether & -78 & 91 & 88 \\
\hline 11 & L4/Cu(I) & $\mathrm{Me}_{3} \mathrm{SiOTf}$ & tBuOMe & -78 & 95 & 92 \\
\hline $12^{\mathrm{e}}$ & L4/Cu(I) & $\mathrm{tBuMe}_{2} \mathrm{SiOTf}$ & tBuOMe & -78 & 95 & 95 \\
\hline 13 & L4/Cu(I) & $\mathrm{BF}_{3} \cdot \mathrm{Et}_{2} \mathrm{O}$ & tBuOMe & -78 & 19 & 92 \\
\hline $14^{f}$ & L4/Cu(I) & $\mathrm{BF}_{3} \cdot \mathrm{Et}_{2} \mathrm{O}$ & tBuOMe & -78 & 77 & 97 \\
\hline $15^{f}$ & L4/Cu(I) & $\mathrm{Me}_{3} \mathrm{SiOTf}$ & tBuOMe & -78 & 99 & 97 \\
\hline 168 & L4/Cu(I) & $\mathrm{Me}_{3} \mathrm{SiOTf}$ & tBuOMe & -78 & 100 & 95 \\
\hline 17 & L4/Cu(I) & $\mathrm{Me}_{3} \mathrm{SiOTf}$ & tBuOMe & 0 & 95 & 88 \\
\hline 18 & $\mathrm{~L} 4 / \mathrm{Cu}(\mathrm{I})$ & Me3SiOTf & tBuOMe & -20 & 97 & 97 \\
\hline \multicolumn{7}{|c|}{ 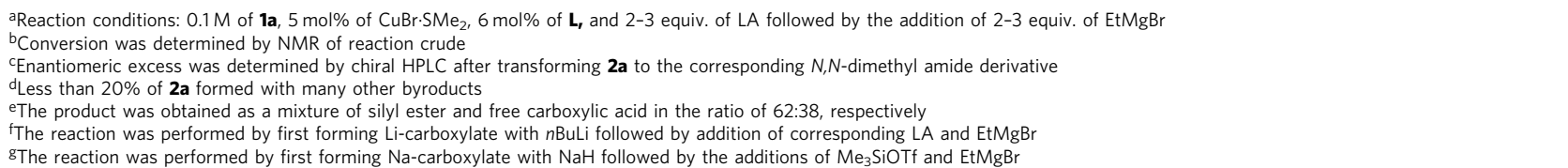 } \\
\hline
\end{tabular}

reactivity has nothing to do with a better solubility, and can be attributed to a higher nucleophilicity of the $\mathrm{Li}^{-}$and $\mathrm{Na}$ carboxylate most likely. Possible explanation for such a difference in reactivity might be higher aggregation state of the $\mathrm{Mg}$ carboxylate that diminishes its nucleophilicity.

Development of catalytic asymmetric reaction. Having established that the boron and silyl intermediates B-B and, especially, B-Si are indeed formed under the right conditions and lead to the racemic product $\mathbf{2 a}$, we shifted our attention to the question whether this reaction system would be susceptible to asymmetric catalysis in order to both accelerate the conjugate addition toward higher yields and achieve enantiocontrol. As copper is known to be an efficient catalyst for asymmetric conjugate addition reactions ${ }^{5-7}$, we started our investigation by selecting various chiral ligands that can bind to $\mathrm{Cu}(\mathrm{I})$. As expected, initial experiments in $\mathrm{CH}_{2} \mathrm{Cl}_{2}$ showed no addition of the highly reactive $\mathrm{EtMgBr}$ to $\mathbf{1 a}$ when performing the reaction in the presence of $5 \mathrm{~mol} \%$ of $\mathbf{L 1} / \mathrm{Cu}$ (I)-catalyst at $-78{ }^{\circ} \mathrm{C}$. Raising the temperature to $0{ }^{\circ} \mathrm{C}$ resulted in $79 \%$ conversion with only $20 \%$ toward noncatalyzed addition product $\mathbf{2 a}$ and many byproducts (Table 1 , entries 1 and 2). At this point, we decided to investigate catalytic reactions in the presence of $\mathrm{Me}_{3} \mathrm{SiOTf}$ (via the formation of the most reactive intermediate $\mathbf{B}-\mathbf{S i}$ ) and copper complexes with various chiral diphosphine ligands in $\mathrm{CH}_{2} \mathrm{Cl}_{2}$ at $-78^{\circ} \mathrm{C}$. Several chiral catalytic systems result in both acceleration of the conjugate addition and in significant enantiodiscrimination (Table 1, entries 3-7). The superior yield and enantioselectivity obtained with diphosphine Tol-BINAP ligand ( $R$ )-L4 (Table 1, entry 6) prompted us to select it as the optimal ligand for this reaction. Subsequently, a thorough optimization process was executed using the catalytic system derived from $\mathbf{L} 4 / \mathrm{CuBr} \cdot \mathrm{SMe}_{2}$ involving the evaluation of various parameters and reaction conditions (for complete set of data see Supplementary Tables 1-5). In particular, the effect of different solvents was studied. With the exception of THF, all solvents tested were effectively tolerated, providing $\mathbf{2 a}$ with good yields and ee (Table 1, entries 8-11). We were especially pleased to find exceptionally high yield (95\%) and enantioselectivity $(92 \% e e)$ in $t$ BuOMe (Table 1 , entry 11 ).

In order to connect catalytic asymmetric addition with the results of our ${ }^{1} \mathrm{H}$ NMR spectroscopic studies using $t \mathrm{BuMe}_{2} \mathrm{SiOTf}$, we tested the addition of EtMgBr to substrate 1a using this Lewis acid. As expected, we found that the reaction proceeds with excellent conversion toward the addition product, providing the final product as a mixture of $t \mathrm{BuMe}_{2} \mathrm{Si}$-ester and free carboxylic acid $2 \mathbf{a}$ in a ratio of 62:38, respectively, and high enantioselectivity (95\% ee, Table 1, entry 12). This composition of the product mixture is not surprising, as under these reaction conditions $t \mathrm{BuMe}_{2} \mathrm{Si}$-ester is expected to be relatively stable.

Catalytic reaction with $\mathrm{L4} / \mathrm{CuBr} \cdot \mathrm{SMe}_{2}$ in $t \mathrm{BuOMe}$ was also investigated using $\mathrm{BF}_{3} \cdot \mathrm{Et}_{2} \mathrm{O}$ as a Lewis acid. Although high level of enantiomeric purity $(92 \%$ ee) could be obtained in this case, lower reactivity toward conjugate addition of Grignard reagent (only 19\% of conversion to $\mathbf{2 a}$ ), similar to that observed earlier for racemic reaction was also found in this case (Table 1, entry 13). In contrast, high yield and enantioselectivitiy can be obtained when using $\mathrm{BF}_{3} \cdot \mathrm{Et}_{2} \mathrm{O}$ in combination with $\mathrm{Li}$ carboxylate (formed by $n \mathrm{BuLi}$ in-situ) followed by addition of 
EtMgBr (Table 1, entry 14). Similar excellent results were found when using $\mathrm{Me}_{3} \mathrm{SiOTf}$ in combination with $\mathrm{Li}^{-}$and $\mathrm{Na}$ carboxylates (formed by $n \mathrm{BuLi}$ and $\mathrm{NaH}$, respectively) followed by addition of EtMgBr (Table 1, entries 15 and 16). However, $\mathrm{Me}_{3} \mathrm{SiOTf}$ was selected as the Lewis acid of choice for further studies because of the convenience of a procedure using only one organometallic reagent and highest conversion obtained (Table 1, entry 11). Since a temperature of $-78^{\circ} \mathrm{C}$ is not practical, particularly for large-scale synthesis, we evaluated the temperature as well (Table 1, entries 17 and 18), finding that $-20^{\circ} \mathrm{C}$ is the optimal temperature for the reaction with the Grignard reagent, the chiral $\mathrm{L4} / \mathrm{Cu}(\mathrm{I})$ catalyst system, and $\mathrm{Me}_{3}$ SiOTf. Under these optimized conditions, the reaction is completed in $2 \mathrm{~h}$ providing the final product $\mathbf{2 a}$ with $97 \%$ of conversion and an ee of $97 \%$ (Table 1, entry 17).

Scope of the reaction. With the optimized conditions in hand, initial efforts to explore the scope of this transformation focused on investigating the effect of varying the carboxylic acid substitution at the $\beta$-position (Fig. 4). A wide variety of substrates allow efficient transformation to the corresponding chiral $\beta$ substituted carboxylic acids. The substrates with linear and branched aliphatic chains (including cyclohexyl and cyclopropyl) gave the corresponding addition products $\mathbf{2 a - 2 d}$ with high yields and excellent enantioselectivities. However, when we applied this condition to the aromatic substrate 1e, only $57 \%$ ee was obtained for product $\mathbf{2 e}$.

Further optimization (see Supplementary Table 5) revealed a different catalytic system to be optimal for aromatic substrates, based on diphosphine ligand $(R, R)$-L5 in combination with copper salt and lower temperatures. Using $10 \mathrm{~mol} \%$ of $\mathbf{L 5} / \mathrm{Cu}(\mathrm{I})$ as the catalyst at $-40{ }^{\circ} \mathrm{C}$ provided the product $2 \mathrm{e}$ with $91 \%$ enantiopurity and $74 \%$ isolated yield (Fig. 4).

An aromatic ring with an electron-donating (methoxy, $2 \mathbf{f}$ ) or electron-withdrawing group $(\mathrm{Br}, \mathbf{2} \mathbf{~ g})$, as well as a heteroaromatic ring $(\mathbf{2} \mathbf{h}, \mathbf{2} \mathbf{i})$, are well tolerated, but including a $m$-Br-substituent in the aromatic ring led to the addition product $\mathbf{2 g}$ with lower yield $(54 \%)$ and $e e(86 \%)$. When the aromatic ring is at the $\gamma$ position, the substrates behave as aliphatic substrates, and the highest levels of ee and conversion are obtained with the catalyst $\mathbf{L} \mathbf{4} / \mathrm{Cu}(\mathrm{I})$ (products $\mathbf{2 j}$ and $\mathbf{2 k}$ ). Finally, our catalytic system tolerates the presence of functional groups in the substrate, providing the corresponding products $(\mathbf{2} \mathbf{1}, \mathbf{2 m})$ with high yields and ees above $96 \%$. Next, we examined the nucleophile scope, starting our investigation with the smallest and least reactive of all Grignard reagents, $\mathrm{MeMgBr}$ (Fig. 4). Methylations are highly relevant for building chiral polymethylated arrays commonly found in natural products, but they pose difficulties because of the low reactivity of methylating reagents in general ${ }^{7,26,27}$. Currently, asymmetric addition of $\mathrm{MeMgBr}$ to $\alpha, \beta$-unsaturated esters is only successful with aliphatic substrates 26,27 .

To our delight, our catalytic system solves this long-standing problem, as it works with similar efficiency for both aliphatic and aromatic substrates, leading to final methylated carboxylic acids with excellent yields and ees (3a, 3b, and 3c). All alkyl Grignard reagents afforded addition products with excellent results, independent of the chain length and branching. The sterically demanding $\alpha-, \beta-$, and $\gamma$-branched Grignard reagents are tolerated, providing products $\mathbf{3 d}-\mathbf{3 f}$ with high yields and enantioselectivities (ees exceeding 95\%). Grignard reagents bearing olefinic substituents also function well, affording the corresponding product $\mathbf{3 g}$ with excellent $e e$ and yield. Products $\mathbf{3 h}$ and $\mathbf{3 i}$, derived from additions of the linear Grignard reagent $(n \mathrm{HexMgBr})$ to $\mathbf{1 a}$ and crotonic acid, respectively, were obtained with high enantiopurities and yields as well.
A few important practical aspects of this chemistry deserve to be highlighted (see Supplementary Table 6). First is the possibility to recycle the catalyst, which can be recovered from the reaction mixture with $83 \%$ isolated yield in the form of chiral $\mathrm{Cu}$ complex and reused in the next reaction with similar performance. Furthermore, the catalyst loading can be decreased from 5 to 1 mol\% for addition reactions to aliphatic substrates, and the reaction can be carried out with similar outcome in 1 -g scale of the substrate. Finally, an additional benefit of this catalytic system is that when substrate conversion exceeds $97 \%$ most products can be obtained by simple acid-base extraction rather than time consuming column chromatography, which is important for large-scale industrial application ${ }^{7}$.

Application of the catalytic methodology. To showcase the potential of our catalytic protocol for future applications, we demonstrate that $\beta$-chiral substituted carboxylic acids can easily be transformed into a variety of valuable molecules (Fig. 5). The first applications that illustrate utility pertain to the use of our chiral products in stereoselective decarboxylative cross-coupling reactions. Decarboxylative cross-coupling reactions are developing very rapidly, and various catalytic systems utilizing aliphatic carboxylic acids (mainly achiral) leading to diverse structural motives have been established over the past decade ${ }^{14-19}$. Here, we demonstrate how useful chiral analogues of those structural motives can be obtained by combining our methodology and decarboxylative couplings (Fig. 5a-c). Nickel-catalyzed decarboxylative alkylation and borylation of product $\mathbf{2 k}$ afforded chiral alkane $\mathbf{4 a}$ and chiral $\beta$-substituted boronate ester $\mathbf{4 b}$, maintaining the original enantiopurity of the starting material through the process $(96 \% \text { ee, Fig. } 5 a)^{16,17}$. Silver-catalyzed decarboxylative bromination of carboxylic acid $\mathbf{3 b}$ lead to the $\beta$-chiral alkyl bromide $4 \mathrm{c}$ with an ee of $99 \%$ (Fig. 5 b) ${ }^{18}$, while Ag-catalyzed decarboxylative azidation of carboxylic acid $\mathbf{3 h}$ provided chiral $\beta$-substituted azide 4d, which was further transformed into chiral triazole $4 \mathbf{e}$ via click reaction, once again without any racemization $(98 \% \text { ee) (Fig. 5c) })^{19}$. Although some similar molecules can be obtained via other catalytic asymmetric methodologies, these are often limited to specific structures and feature varying levels of enantioselectivities ${ }^{33,34}$. For example, chiral $\beta$-substituted boronate esters can also be obtained through transition metal catalyzed hydroboration of 1,1-disubstituted alkenes. However, these methods are only effective when an aryl group or directing carbonyl groups are present in the substrate. Applying $\beta$-substituted carboxylic acids obtained by our methodology in decarboxylative borylation offers an attractive alternative for accessing a wide range of chiral aliphatic $\beta$-substituted boronate esters.

Our methodology is also sufficiently mild and robust to be applied in more complex molecules. For example, UVI3003 5a, a full antagonist of RXR (one of the retinoid receptors involved in the control of various physiological and pathological processes, including cancer and metabolic diseases) that demonstrates potent, nanomolar binding affinity ${ }^{35}$, can be functionalized successfully with our strategy without prior protection of the hydroxyl group and afford the product $\mathbf{5 b}$ with $76 \%$ yield and $99 \%$ ee (Fig. 5d). Another synthetically useful transformation available with our methodology is the trapping of enolate intermediates formed upon conjugate addition (Fig. 5e). For instance, while conjugate addition product 21 can be obtained with $88 \%$ yield and $96 \%$ ee, modifying the original procedure by using $\mathrm{Li}$-carboxylate for asymmetric conjugate addition at $-78{ }^{\circ} \mathrm{C}$, followed by warming up to room temperature and stirring overnight, leads to intramolecular enolate trapping, affording the cyclic product 


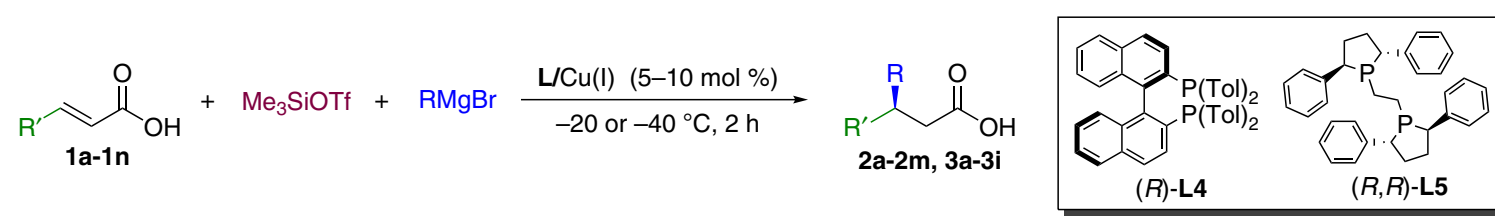

Scope of $\beta$-substituents of the $\alpha, \beta$-unsaturated carboxylic acids for additions of EtMgBr $\mathrm{r}^{2, b}$<smiles>CCC[C@H](CC)CC(=O)O</smiles>

2a, with L4 at $-20{ }^{\circ} \mathrm{C}$ : $91 \%$ yield, $97 \% e e^{c}$<smiles>CCC(C)CC(=O)O</smiles>

2b, with L4 at $-20{ }^{\circ} \mathrm{C}$ : $74 \%$ yield, $95 \%$ ee<smiles>CCC(CC(=O)O)C1CCCCC1</smiles>

2c, with $\mathbf{L 4}$ at $-20^{\circ} \mathrm{C}$ : $83 \%$ yield, $98 \%$ ee<smiles>CC[C@H](CC(=O)O)C1CC1</smiles>

2d, with $\mathbf{L} 4$ at $-20^{\circ} \mathrm{C}$. $83 \%$ yield, $93 \%$ ee<smiles>CC[C@H](CC(=O)O)c1ccccc1</smiles>

2e, with $\mathbf{L 5}$ at $-40{ }^{\circ} \mathrm{C}$ : $74 \%$ yield, $91 \%$ ee<smiles>CC[C@H](CC(=O)O)Cc1ccccc1</smiles>

2j, with $\mathbf{L} 4$ at $-40{ }^{\circ} \mathrm{C}$ : $70 \%$ yield, $97 \%$ ee<smiles>CC[C@@H](CC(=O)O)c1ccc(OC)cc1</smiles>

2f, with $\mathbf{L 5}$ at $-40{ }^{\circ} \mathrm{C}$ : $70 \%$ yield, $91 \%$ ee<smiles>CC[C@H](CC(=O)O)c1cccc(Br)c1</smiles>

$\mathbf{2 g}$, with $\mathbf{L} \mathbf{5}$ at $-40{ }^{\circ} \mathrm{C}$ : $54 \%$ yield, $86 \%$ ee<smiles>CC[C@@H](CC(=O)O)c1cccs1</smiles>

2h, with $\mathbf{L} \mathbf{5}$ at $-40{ }^{\circ} \mathrm{C}$ : $75 \%$ yield, $90 \%$ ee<smiles>CC[C@H](CC(=O)O)c1ccsc1</smiles>

2i, with $\mathbf{L 5}$ at $-40{ }^{\circ} \mathrm{C}$ : $88 \%$ yield, $93 \%$ ee<smiles>CCC(CC(=O)O)Cc1ccc(OC)cc1</smiles>

2k, with $\mathbf{L} 4$ at $-40{ }^{\circ} \mathrm{C}$ : $74 \%$ yield, $96 \%$ ee<smiles>CC[C@H](CCCBr)CC(=O)O</smiles>

2I, with $\mathbf{L} 4$ at $-20{ }^{\circ} \mathrm{C}$ : $88 \%$ yield, $96 \%$ ee<smiles>CC[C@H](CCCOCc1ccccc1)CC(=O)O</smiles>

$2 \mathrm{~m}$, with $\mathbf{L} \mathbf{4}$ at $-20^{\circ} \mathrm{C}$ : $75 \%$ yield, $97 \%$ ee

Scope of Grignard reagents in the addition to $1 a, 1 b$ and $1 e^{a, b}$

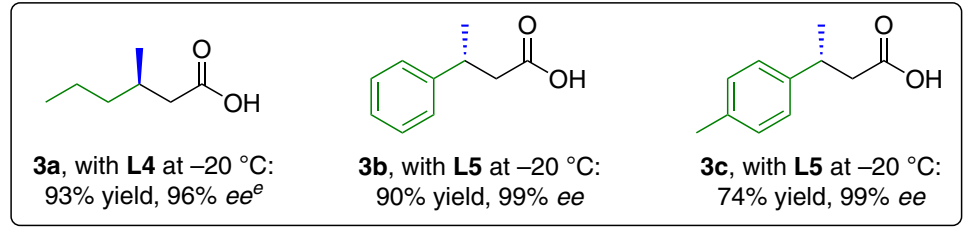

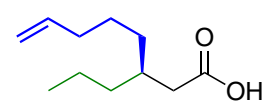

3g, with L4 at $-20{ }^{\circ} \mathrm{C}$ : $85 \%$ yield, $98 \%$ ee<smiles>CCCCCCC(CCC)CC(=O)O</smiles>

3h, with $\mathbf{L} 4$ at $-20{ }^{\circ} \mathrm{C}$ : $79 \%$ yield, $98 \%$ ee<smiles>CCCC(CC(=O)O)CC(C)C</smiles>

3e, with $\mathbf{L} 4$ at $-20^{\circ} \mathrm{C}$ : $83 \%$ yield, $95 \%$ ee 3f, with L4 at $-20{ }^{\circ} \mathrm{C}$ : $84 \%$ yield, $98 \%$ ee<smiles>CCCC(CCC(C)C)CC(=O)O</smiles>

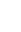

Fig. 4 Scope of the substrate and Grignard reagent. aFor details see Supplementary Information. Isolated yields for all the products are shown. The absolute

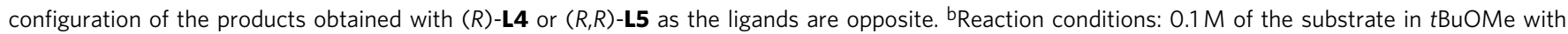

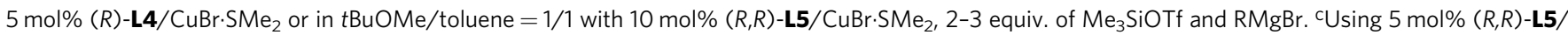
$\mathrm{CuBr} \cdot \mathrm{SMe}_{2}$ as a catalyst in the same condition led to $\mathbf{1 a}$ with $93 \%$ ee. dUsing $5 \mathrm{~mol} \%(R)-\mathbf{L} \mathbf{4} / \mathrm{CuBr} \cdot \mathrm{SMe} \mathrm{e}_{2}$ as a catalyst led to $\mathbf{2 e}$ with $57 \%$ ee. eThe reaction performed using $10 \mathrm{~mol} \%$ of $(R)$-L4/CuBr.SMe $2 .{ }^{\mathrm{f}}$ The reaction performed at $-40{ }^{\circ} \mathrm{C}$

6 with contiguous stereocenters as a single diastereoisomer (70\% yield, 91\% ee). Recently, chiral indole derivative $7 \mathbf{a}$, synthesized in four steps from the commercially available $(S)$ citronellal, was reported (Fig. 5f) to exhibit in vitro and ex vivo anti-inflammatory properties as a potent 15-lipoxygenase-1 inhibitor $^{36}$. However, as such chiral aldehydes or carboxylic acids are rarely commercially available, synthesis of similar chiral compounds with variations of the alkyl chain is difficult, thus limiting the number of molecules available for bioactivity screening. With our methodology, a library of this type of compounds with different substituents at the $\beta$-position of the acyl group can be straightforwardly accessed in just two steps, as exemplified by the synthesis of $\mathbf{7 b}$ (Fig. $5 \mathrm{~g}$ ). Finally, our methodology allows us to effortlessly obtain the aromatic chiral $\beta$-substituted carboxylic acid 3c (Fig. 5h), which is a key intermediate for the synthesis of several natural products, like $(S)-(+)$-ar-tumerone, $(+)$-bisacumol, and $(S)$-arhimachalene $\mathrm{e}^{37}$.

\section{Discussion}

We have shown that a wide range of $\beta$-chiral carboxylic acids are now synthetically accessible from their unsaturated analogues in one simple step and under mild conditions with high yields and enantioselectivities. Our strategy is based on activation of carboxylic acids via formation of transient silyl or boron intermediates, and it is crucial to overcoming the fundamental problem of carboxylate salt formation during the conjugate 
a<smiles>CCC(CC(=O)O)Cc1ccc(OC)cc1</smiles>

2k, $96 \%$ ee

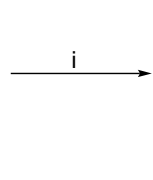

ii

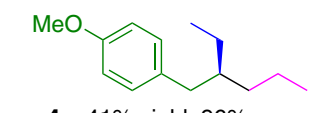

4a, $41 \%$ yield, $96 \%$ ee $\mathrm{MeO}$<smiles>CCC(CB1OC(C)(C)C(C)(C)O1)Cc1ccc(F)cc1</smiles>

$\mathbf{4 b}, 32 \%$ yield, $96 \%$ ee

b

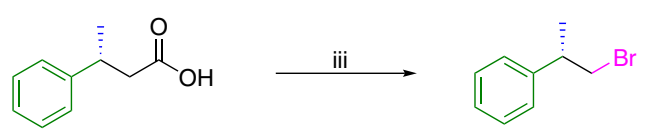

3b, $99 \%$ ee

4c, $46 \%$ yield, $99 \%$ ee<smiles>CCCCCCC(CCC)CC(=O)O</smiles>

$3 \mathrm{~h}, 98 \%$ ee<smiles>CCCCCCC(CN)CCC</smiles>

4d, $53 \%$ yield, $98 \%$ ee

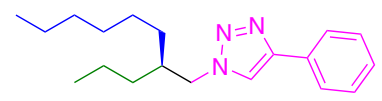

$4 e, 78 \%$ yield, $98 \%$ ee<smiles>CCCCCOc1cc2c(cc1-c1cc(/C=C/C(=O)O)ccc1O)C(C)(C)CCC2(C)Cl</smiles>

5a, UVI3003<smiles>CCCCOc1cc2c(cc1-c1cc([C@H](C)CC(=O)O)ccc1O)C(C)(C)CCC2(C)C</smiles>

5b, $76 \%$ yield, $99 \%$ ee<smiles>CCC(CCCBr)CC(=O)O</smiles>

2I, $88 \%$ yield, $96 \%$ ee

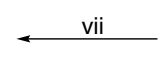

vii f<smiles>CCOC(=O)c1[nH]c2cc(Cl)ccc2c1C(=O)C[C@@H](C)CCCC(C)C</smiles><smiles>O=C(O)/C=C/CCCBr</smiles>

11<smiles>C#CC</smiles><smiles>CCC1CCC[C@H]1C(=O)O</smiles>

6, $70 \%$ yield, $91 \%$ ee

g<smiles>[X]C(C)C</smiles>

7b, $84 \%$ yield, $98 \%$ ee<smiles>Cc1ccc(/C=C/C(=O)O)cc1</smiles>

1n

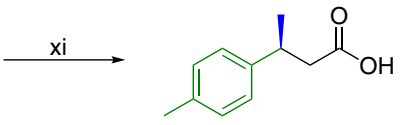

3c, $74 \%$ yield, $99 \%$ ee
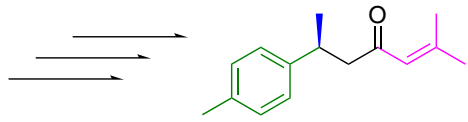

(S)-(+)-ar-tumerone

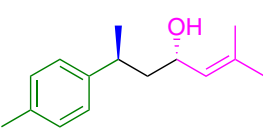

(+)-bisacumol

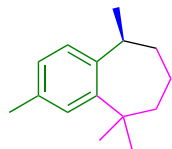

(S)-ar-himachalene

Fig. 5 Synthetic utility of the process. a Ni-catalyzed decarboxylative alkylation and borylation of chiral acid $\mathbf{2 k}$. $\mathbf{b}$ Ag-catalyzed decarboxylative bromination of product $\mathbf{3 b}$. c Ag-catalyzed decarboxylative azidation of chiral acid $\mathbf{3 h}$ followed by click reaction. $\mathbf{d}$ Late-stage functionalization of a RXR antagonist $\mathbf{5 a}$. e Effect of the different procedures on the structure of the final asymmetric conjugate addition of EtMgBr to the carboxylic acid substrate $\mathbf{1 l}$. $\mathbf{f}$ Reported synthetic route to a potent 15-lipoxygenase-1-inhibitor $\mathbf{7 a}$. $\mathbf{g}$ Synthesis of the derivative $\mathbf{7 b}$ in two steps using current methodology. $\mathbf{h}$ Synthesis of chiral

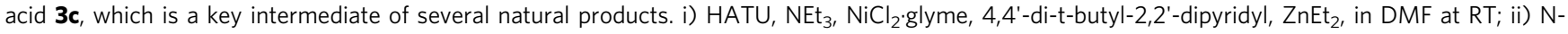
hydroxyphthalimide, $\mathrm{DCC}$, in $\mathrm{CH}_{2} \mathrm{Cl}_{2}$ at RT, $2 \mathrm{~h}$, then $\mathrm{MgBr}_{2} \cdot \mathrm{OEt}_{2}, \mathrm{NiCl}_{2} \cdot 6 \mathrm{H}_{2} \mathrm{O}, 4,4^{\prime}$-dimethoxy-2,2'-bipyridyl, $\left[\mathrm{B}_{2} \mathrm{pin}_{2} \mathrm{Me}\right] \mathrm{Li}$, in DMF, THF, at $0{ }^{\circ} \mathrm{C} 1 \mathrm{~h} \sim \mathrm{RT} 1$ h; iii) $\mathrm{Ag}$ (Phen) $)_{2} \mathrm{OTf}$, dibromoisocyanuric acid, in 1,2-dichloroethane at $60^{\circ} \mathrm{C}$; iv) $\mathrm{AgF}, \mathrm{K}_{2} \mathrm{~S}_{2} \mathrm{O}_{8}, \mathrm{MesSO}_{2} \mathrm{~N}_{3}$ in $\mathrm{CH}_{3} \mathrm{CN}, \mathrm{H}_{2} \mathrm{O}$, at $55^{\circ} \mathrm{C}$; v) phenylacetylene, CuTc, in toluene at $\mathrm{RT}$; vi) $\mathrm{CuBr} \cdot \mathrm{SMe}_{2},(R, R)-\mathbf{L 2}, \mathrm{Me}_{3} \mathrm{SiOTf}, \mathrm{MeMgBr}$, in tBuOMe:Toluene = 1:1, at $-20^{\circ} \mathrm{C}$; vii) $\mathrm{CuBr}_{\mathrm{B}} \mathrm{SMe}{ }_{2},(R)-\mathbf{L 1}, \mathrm{Me}_{3} \mathrm{SiOTf}$, EtMgBr, in

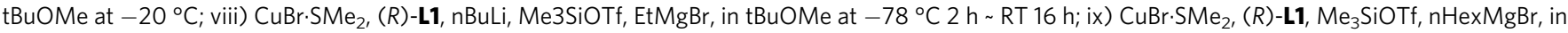
tBuOMe at $\left.-78^{\circ} \mathrm{C} ; \mathrm{x}\right) \mathrm{SOCl}_{2}$, DMF (1 drop), in $\mathrm{CH}_{2} \mathrm{Cl}_{2}$ at RT, $1 \mathrm{~h}$, then ethyl 6-chloro-1H-indole-2-carboxylate, $\mathrm{SnCl}_{4}$, in $\mathrm{CH}_{2} \mathrm{Cl}_{2}, \mathrm{reflux}$; $\mathrm{xi}$ ) $\mathrm{CuBr}_{\mathrm{SMe}}$, $(\mathrm{S}$, S)-L2, $\mathrm{Me}_{3} \mathrm{SiOTf}, \mathrm{MeMgBr}$, in tBuOMe:Toluene $=1: 1$ at $-20{ }^{\circ} \mathrm{C}$

addition of organometallics to unsaturated carboxylic acid. Thus, this approach allows highly enantioselective catalytic $\mathrm{C}-\mathrm{C}$ bondforming reactions between organometallics and carboxylic acids without the use of separate protection/deprotection steps.

\section{Methods}

General procedure for the catalytic reaction. In a flame-dried Schlenk tube equipped with septum and magnetic stirring bar, the carboxylic acid substrate ( $0.2 \mathrm{mmol}, 1.0$ equiv.), $\mathrm{CuBr} \cdot \mathrm{SMe}_{2}(0.01 \mathrm{mmol}, 5 \mathrm{~mol} \%)$, and ligand $\mathbf{L}(0.012 \mathrm{mmol}$, $6 \mathrm{~mol} \%)$ were dissolved in the solvent $(2.0 \mathrm{~mL})$ and stirred under nitrogen atmosphere for $20 \mathrm{~min}$ at RT. The mixture was cooled to -20 or $-40^{\circ} \mathrm{C}$, and $\mathrm{Me}_{3} \mathrm{SiOTf}$ ( $0.44 \mathrm{mmol}, 2.2$ equiv.) was added. After $20 \mathrm{~min}, \mathrm{RMgBr}(0.5 \mathrm{mmol}, 2.5$ equiv.) was added dropwise by hand in 10 min (syringe pump use is also an option), and the reaction mixture was allowed to stir for $2 \mathrm{~h}$.

General work-up procedure A. Upon reaction completion, the mixture was quenched with $\mathrm{HCl}$ aqueous solution $(2.0 \mathrm{~mL}, 1.0 \mathrm{M})$ and warmed up to RT. The resulting mixture was extracted with $\mathrm{CH}_{2} \mathrm{Cl}_{2}(10.0 \mathrm{~mL} \times 3)$. The combined organic phase was dried over $\mathrm{MgSO}_{4}$, filtered, and the solvent was evaporated on a rotary evaporator. Pentane $(1.0 \mathrm{~mL} \times 3)$ was added to the residue, and the mixture was filtered through a cotton in a small glass pipette in order to remove the catalyst. The crude was purified by flash chromatography on the silica gel to yield the final conjugate addition product after solvent removal.

General work-up procedure B. Upon reaction completion, the mixture was quenched with saturated $\mathrm{NaHCO}_{3}$ aqueous solution $(2.0 \mathrm{~mL})$, warmed up to room 
temperature, and the organic phase was extracted. The organic phase was further extracted with saturated $\mathrm{NaHCO}_{3}$ aqueous solution $(2.0 \mathrm{~mL})$ for another two times. The combined aqueous phase was acidified with $\mathrm{HCl}$ aqueous solution $(1.5 \mathrm{~mL}$, $12.0 \mathrm{M})$, and extracted with $\mathrm{CH}_{2} \mathrm{Cl}_{2}(10.0 \mathrm{~mL} \times 3)$. The combined organic phase was dried over $\mathrm{MgSO}_{4}$, filtered, and the solvent was evaporated on a rotary evaporator to yield the final conjugate addition product.

Procedure for the preparative-scale reaction. In a flame-dried three-neck roundbottom flask equipped with the septum and mechanistic stirring bar, the substrate 1a (1.14 g, $10.0 \mathrm{mmol}$, 1.0 equiv.), $\mathrm{CuBr} \cdot \mathrm{SMe}_{2}(102.8 \mathrm{mg}, 0.5 \mathrm{mmol}, 5 \mathrm{~mol} \%$ ), and ligand (R)-L4 $(407.3 \mathrm{mg}, 0.6 \mathrm{mmol}, 6 \mathrm{~mol} \%)$ were dissolved in $t \mathrm{BuOMe}(50 \mathrm{~mL})$, and the mixture was stirred under nitrogen atmosphere for $20 \mathrm{~min}$ at RT. The mixture was cooled to $-20{ }^{\circ} \mathrm{C}$ and $\mathrm{Me}_{3} \mathrm{SiOTf}(3.98 \mathrm{~mL}, 22 \mathrm{mmol}, 2.2$ equiv.) was added. After $20 \mathrm{~min}, \mathrm{EtMgBr}$ ( $8.33 \mathrm{~mL}, 25 \mathrm{mmol}, 2.5$ equiv.) was added with the syringe pump in $20 \mathrm{~min}$, and the reaction mixture was allowed to stir for another $2 \mathrm{~h}$ at $-20^{\circ} \mathrm{C}$. The reaction was quenched with water $(10.0 \mathrm{~mL})$ and warmed to RT. The aqueous phase was discarded, and the organic phase was extracted with saturated $\mathrm{NaHCO}_{3}$ aqueous solution $(50.0 \mathrm{~mL} \times 3)$. In this step, the chiral catalyst $\mathrm{L} 4 / \mathrm{Cu}(\mathrm{I})$ remains in the organic phase, while the product $\mathbf{2 a}$ is in the aqueous phase. The organic phase was washed with $\mathrm{HCl}$ aqueous solution $(10.0 \mathrm{~mL}, 1.0 \mathrm{M})$, dried over $\mathrm{MgSO}_{4}$, filtered and evaporated on a rotary evaporator. The residue was rinsed with a little amount of pentane, and dried in vacuo overnight to afford the recovered chiral catalyst $\mathbf{L} 4 / \mathrm{Cu}(\mathrm{I})$ as a light yellow powder [ $83 \%$ yield]. The combined aqueous phase was acidified with $\mathrm{HCl}$ aqueous solution $(50.0 \mathrm{~mL}, 12.0 \mathrm{M})$, and extracted with $\mathrm{CH}_{2} \mathrm{Cl}_{2}(100.0 \mathrm{~mL} \times 3)$. The combined organic phase was dried over $\mathrm{MgSO}_{4}$, filtered, and evaporated on a rotary evaporator to yield the product $\mathbf{2 a}$ as a colorless oil $[83 \%$ yield, $97 \% e e]$.

\section{Data availability}

The authors declare that the data supporting the findings of this study are available within the article and the Supplementary Information, as well as from the authors upon reasonable request. Supplementary Information and chemical compound information are available in the online version of the paper. For the optimization of reaction conditions, see Supplementary Tables 1-5. For practical aspects of the reaction, see Supplementary Table 6. For the experimental details and product characterization, see Supplementary Methods. For the formation, conjugate addition and NMR studies of unsaturated silyl ester, see Supplementary Methods. For the isolation, reactivity and measurement of the solubility of Mg-, Li-, and Na-carboxylates, see Supplementary Methods. For NMR analysis and HPLC traces of the compounds in this article, see Supplementary Figs. 1-75.

Received: 25 June 2019 Accepted: 9 July 2019

Published online: 30 July 2019

\section{References}

1. Maag, H. Prodrugs of Carboxylic Acids (Springer, New York, 2007).

2. Gminsights.com. Carboxylic Acid Market Size, Share - Industry Outlook Report 2024. https://www.gminsights.com/industry-analysis/carboxylic-acidmarket [Accessed 26 June 2019] (2019).

3. Gooßen, L. J., Rodríguez, N. \& Gooßen, K. Carboxylic acids as substrates in homogeneous catalysis. Angew. Chem. Int. Ed. 47, 3100-3120 (2008).

4. Perlmutter, P. Conjugate Addition Reactions in Organic Synthesis. (Tetrahedron Organic Chemistry, Series 9, Pergamon, Oxford, 1992).

5. Alexakis, A., Krause, N. \& Woodward, S. Copper-Catalyzed Asymmetric Synthesis (Wiley-VCH, Weinheim, Germany, 2014).

6. Harutyunyan, S. R., den Hartog, T., Geurts, K., Minnaard, A. J. \& Feringa, B. L. Catalytic asymmetric conjugate addition and allylic alkylation with Grignard reagents. Chem. Rev. 108, 2824-2852 (2008).

7. Howell, G. P. Asymmetric and diastereoselective conjugate addition reactions: C-C bond formation at large scale. Org. Process Res. Dev. 16, 1258-1272 (2012).

8. Wotiz, J. H., Matthews, J. S. \& Greenfield, H. The reaction of Grignard reagents with $\alpha, \beta$-olefinic acids. J. Am. Chem. Soc. 75, 6342-6343 (1953).

9. Yamamoto, Y. \& Maruyama, K. RCu. $\mathrm{BF}_{3}$. 3. Conjugate addition to previously unreactive substituted enoate esters and enoic acids. J. Am. Chem. Soc. 100, 3240-3241 (1978)

10. Cooke, M. P. Jr. Conjugate addition reactions of $\alpha$-silylated $\alpha, \beta$-unsaturated carboxylic acid salts. J. Org. Chem. 52, 5729-5733 (1987).

11. Aurell, M. J., Domingo, L. R., Mestres, R., Muñoz, E. \& Zaragozá, R. J. Conjugate addition of organolithium reagents to $\alpha, \beta$-unsaturated carboxylic acids. Tetrahedron 55, 815-830 (1999).

12. Vautravers, N. R. \& Breit, B. Rhodium (I)-catalyzed 1,4-addition of arylboronic acids to acrylic acid in water: one-step preparation of 3arylpropionic acids. Synlett. 17, 2517-2520 (2011).
13. Liu, R. et al. $\mathrm{Pd}(\mathrm{II}) /$ bipyridine-catalyzed conjugate addition of arylboronic acids to $\alpha, \beta$-unsaturated carboxylic acids. Synthesis of $\beta$-quaternary carbons substituted carboxylic acids. J. Org. Chem. 82, 8023-8030 (2017).

14. Xuan, J., Zhang, Z.-G. \& Xiao, W.-J. Visible-light-induced decarboxylative functionalization of carboxylic acids and their derivatives. Angew. Chem. Int Ed. 54, 15632-15641 (2015).

15. Schwarz, J. \& König, B. Decarboxylative reactions with and without light - a comparison. Green. Chem. 20, 323-361 (2018).

16. Qin, T. et al. A general alkyl-alkyl cross-coupling enabled by redox-active esters and alkylzinc reagents. Science 352, 801-805 (2016).

17. Li, C. et al. Decarboxylative borylation. Science 356, 1045 (2017).

18. Tan, X. et al. Silver-catalyzed decarboxylative bromination of aliphatic carboxylic acids. Org. Lett. 19, 1634-1637 (2017).

19. Zhu, Y. et al. Silver-catalyzed decarboxylative azidation of aliphatic carboxylic acids. Org. Lett. 17, 4702-4705 (2015).

20. Sun, X., Zhou, L., Wang, C.-J. \& Zhang, X. Rh-catalyzed highly enantioselective synthesis of 3-arylbutanoic acids. Angew. Chem. Int. Ed. 46, 2623-2626 (2007).

21. Murai, K. et al. Kinetic resolution of $\beta$-substituted olefinic carboxylic acids by asymmetric bromolactonization. Org. Lett. 15, 2526-2529 (2013).

22. Khumsubdee, S. \& Burgess, K. Comparison of asymmetric hydrogenations of unsaturated carboxylic acids and esters. ACS Catal. 3, 237-249 (2013).

23. Yang, S., Che, W., Wu, H.-L., Zhu, S.-F. \& Zhou, Q.-L. Neutral iridium catalysts with chiral phosphine-carboxy ligands for asymmetric hydrogenation of unsaturated carboxylic acids. Chem. Sci. 8, 1977-1980 (2017).

24. Chiacchio, U. et al. Syntheses of new chiral bicyclic sultams and their use as auxiliaries in asymmetric conjugate addition of Grignard reagents. Tetrahedron.: Asymmetry 13, 1915-1921 (2002).

25. López, F., Harutyunyan, S. R., Meetsma, A., Minnaard, A. J. \& Feringa, B. L. Copper-catalyzed enantioselective conjugate addition of Grignard reagents to $\alpha, \beta$-unsaturated esters. Angew. Chem. Int. Ed. 44, 2752-2756 (2005).

26. Des Mazery, R. et al. An iterative catalytic route to enantiopure deoxypropionate subunits: asymmetric conjugate addition of Grignard reagents to $\alpha, \beta$-unsaturated thioesters. J. Am. Chem. Soc. 127, $9966-9967$ (2005).

27. Wang, S.-Y. \& Loh, T.-P. Highly enantioselective $\mathrm{Cu}(\mathrm{I})-$ Tol-BINAP-catalyzed asymmetric conjugate addition of Grignard reagents to $\alpha, \beta$-unsaturated esters. Chem. Commun. 46, 8694-8703 (2010).

28. Rodríguez-Fernández, M., Yan, X., Collados, J. F., White, P. B. \& Harutyunyan, S. R. Lewis acid enabled copper-catalyzed asymmetric synthesis of chiral $\beta$-substituted amides. J. Am. Chem. Soc. 139, 14224-14231 (2017).

29. Zhou, Y., Bandar, J. S., Liu, R. Y. \& Buchwald, S. L. CuH-catalyzed asymmetric reduction of $\alpha, \beta$-unsaturated carboxylic acids to $\beta$-chiral aldehydes. J. Am. Chem. Soc. 140, 606-609 (2018).

30. Mu, Y., Nguyen, T. T., van der Mei, F. W., Schrock, R. R. \& Hoveyda, A. H. Traceless protection for more broadly applicable olefin metathesis. Angew. Chem. Int. Ed. 58, 5365-5370 (2019).

31. Rong, J., Oost, R., Desmarchelier, A., Minnaard, A. J. \& Harutyunyan, S. R. Catalytic asymmetric alkylation of acylsilanes. Angew. Chem. Int. Ed. 54, 3038-3042 (2015)

32. Jumde, R. P., Lanza, F., Veenstra, M. J. \& Harutyunyan, S. R. Catalytic asymmetric addition of Grignard reagents to alkenyl-substituted aromatic $\mathrm{N}$ heterocycles. Science 352, 433-437 (2016).

33. Norsikian, S., Marek, I., Klein, S., Poisson, J. F. \& Normant, J. F. Enantioselective carbometalation of cinnamyl derivatives: new access to chiral disubstituted cyclopropanes-configurational stability of benzylic organozinc halides. Chem. Eur. J. 5, 2055-2068 (1999).

34. Jang, W. J., Song, S. M., Moon, J. H., Lee, J. Y. \& Yun, J. Copper-catalyzed enantioselective hydroboration of unactivated 1,1-disubstituted alkenes. J. Am. Chem. Soc. 139, 13660-13663 (2017).

35. Nahoum, V. et al. Modulators of the structural dynamics of the retinoid X receptor to reveal receptor function. Proc. Natl Acad. Sci. USA 104, 17323-17328 (2007).

36. Eleftheriadis, N. et al. Rational development of a potent 15-lipoxygenase-1 inhibitor with in vitro and ex vivo anti-inflammatory properties. J. Med. Chem. 58, 7850-7862 (2015).

37. Yan, Q., Kong, D., Li, M., Hou, G. \& Zi, G. Highly efficient Rh-catalyzed asymmetric hydrogenation of $\alpha, \beta$-unsaturated nitriles. J. Am. Chem. Soc. 137, 10177-10181 (2015)

\section{Acknowledgements}

Financial support from The Netherlands Organization for Scientific Research (NWOVICI to S.R.H.), the China Scholarship Council (CSC, to X.Y.), and the Ministry of Education, Culture, and Science (Gravity program 024.001 .035 to S.R.H.) is acknowledged.

\section{Author contributions}

X.Y. and S.R.H. conceived the work. X.Y. designed and performed the experiments and analyzed the data. S.R.H. guided the research. 


\section{Additional information}

Supplementary Information accompanies this paper at https://doi.org/10.1038/s41467019-11345-z.

Competing interests: The authors declare no competing interests.

Reprints and permission information is available online at http://npg.nature.com/ reprintsandpermissions/

Peer review information: Nature Communications thanks anonymous reviewer(s) for their contribution to the peer review of this work.

Publisher's note: Springer Nature remains neutral with regard to jurisdictional claims in published maps and institutional affiliations. (c) (i) Open Access This article is licensed under a Creative Commons Attribution 4.0 International License, which permits use, sharing, adaptation, distribution and reproduction in any medium or format, as long as you give appropriate credit to the original author(s) and the source, provide a link to the Creative Commons license, and indicate if changes were made. The images or other third party material in this article are included in the article's Creative Commons license, unless indicated otherwise in a credit line to the material. If material is not included in the article's Creative Commons license and your intended use is not permitted by statutory regulation or exceeds the permitted use, you will need to obtain permission directly from the copyright holder. To view a copy of this license, visit http://creativecommons.org/ licenses/by/4.0/

(C) The Author(s) 2019 